\title{
WHAT IS IN A NICKNAME: GHANAIAN NICKNAME CULTURES
}

\author{
Albert Kanlisi Awedoba* \\ \& \\ Stephen Owoahene-Acheampong* \\ http://dx.doi.org/10.4314/og.v13i 1.8
}

\begin{abstract}
Many a Ghanaian at one time or the other in his or her life has either been given a nickname, or conferred one on himself or herself, or on another person. Some have not one but several and a nickname may supplant a birth name. Some nicknames are perceived as insulting and are resented but some too are welcomed even if on the surface they denigrate the bearer. The paper looks at the characteristics of nicknames in Ghana. It addresses the questions: who gives nicknames; to whom; for what reasons; and what significant values do they have? It posits that the study of nicknames contributes to an appreciation of the socio-cultural values of a society.
\end{abstract}

Keywords: nicknames, names, culture, Ghana, Africa

\section{Introduction}

What is in a name: Shakespearian rhetorical question, Academics among others, have posed the same question (see Carter (1944: 242); Connolly (2000), and Odotei (1989)), though not every scholar accepts the Shakespearian postulate on the emptiness of names. Nevertheless, it might just as well also be asked: what is in a nickname? The issue of nicknames, like any other social norm, invites us to consider its make-up and its raison d'être, and whatever insights it might shed on socio-cultural issues, as well as any implications for law and public administration. Given that individuals have their formal names, many of which suggest their ethnicity, personal and family history and other features of their society, and which 
enable them to be identified and individualised, at first sight nicknames would seem superfluous and unnecessary. Nicknames invite questions, such as who gives them, to whom and for what reasons, and who accepts or rejects them. In other words, what do nicknames connote, what purpose do they serve, what are their overt and hidden meanings, and in our specific case, whether a culture of Ghanaian nicknaming exists, and if so, its significance. ${ }^{1}$ These are issues that this paper will attempt to address. In this paper we will show that a number of factors explain nicknames. While Shakespeare might insist on the opacity of names, we contend here that nicknames in particular often reflect the perceived character of the name bearer and his/her place in community and the issues of the nickname giver; and that the study of nicknames contributes to an appreciation of the socio-cultural values of a society.

\section{Defining Nickname}

Nickname has been defined by the Merriam Webster Dictionary (MWD) as 'a name ... that is different from your real name but is what your family, friends, etc., call you when they are talking to you or about you'. ${ }^{2}$ The English word 'nickname' is enigmatic. It is said to have originated from the Anglo-Saxon 'ekename', which segments into the prefix 'eke-' which meant 'also' or 'added' and '-name'. With time ekename evolved into nekename and ultimately 'nickname',

\footnotetext{
${ }^{1}$ The information used in this paper is derived from multiple sources including field research and interviews with randomly selected individuals of various ethnic backgrounds in Accra (Akan, Ewe, Ga, Dagbani, etc.). This is complemented by the personal experiences of the two authors who between them have lived in a number of Regions of the country, particularly, the three Northern Regions, Ashanti and Greater Accra. Media and library resources also came in handy. In all 80 people were interviewed.

${ }^{2}$ See $<$ http://www.merriam-webster.com/dictionary/nickname>, accessed 10 October 2014.
} 
according to MWD. If this information is correct, then nickname from the Anglo-Saxon viewpoint is an added or additional name, perhaps an alternate name or alias that a person bears. ${ }^{3}$ The MWD definition makes the essential point that nicknames may be addressive (used to call or address their bearers) and/or referential (used in referring to a person). Nicknames that border on insults are more likely to be referential than addressive and may be uttered behind the individual's back. They are also more likely to be resented and to provoke a quarrel. The Greeks had their hupokorisma, literally, 'calling by an endearing name'. It is suggested that in ancient times Anglo-Saxon communities did not have surnames, which meant that since there were a limited number of names circulating within the community many people answered to the same name. Thus, to differentiate between individuals nicknames came into play and from such nicknames some English surnames eventually emerged. ${ }^{4}$

On Spanish nicknames Gilmore (1982) argues that they serve as mechanisms of social control within a community, as well as solidarity enhancers signalling friendships, kinship and other community or group ties. They thus serve as boundary

\footnotetext{
${ }^{3}$ It seems that it is not only humans who bear nicknames, animals, objects and artefacts also do. In Accra we have the State House which used to be called 'Job Six Hundred', and the Kwame Nkrumah International Conference Centre is called the 'Pink Lady' because it is imposing and painted pink.

${ }^{4} 2014$
}

Dictionary.com<http://dictionary.reference.com/help/faq/language/e32.html $>$, accessed 8 October 2014.

The situation is not too different from what obtains in some Akan communities in Ghana where the population shares seven day names. Even the addition of common Christian names like Paul, Mary and Peter is not enough to prevent several people in a village being known by the same name. In the Aowin community of Asemkrom in the Enchi District, efforts to trace a Mary Cudjoe proved nearly futile as there were many people bearing that name. 
maintainers. Brandes (1975:142) confirms this, though he also argues that community size and demography influence the presence and vibrancy of nicknames. He writes: 'The nickname phenomenon flourishes where settlements are small, egalitarian, and traditional enough to provide for the moral unity and effective informal sanctioning mechanisms.' Gilmore (1982: 197) sees them as 'injurious sobriquets'aform of verbal aggression that can displace male competition and envy. For Green (1991), observing some New Zealand Waterfront norms, nicknames strike her as double-edged: while they act as behaviour controlling device, at the same time they serve as markers of group membership, i.e. having a nickname serves as a sign of acceptance within the group in which the nickname has gained currency. Brandes (1975) remarks that in some contexts rural Spanish nicknames can be concealed and kept secret from outsiders, and even though they are uttered behind the backs of the nicknamed, that fact nevertheless serves, in the view of Brandes (1975: 43), to assert social solidarity. Glazier (1987: 74) comments on the historicity of Jewish names and their capacity to evoke nostalgic images of life in the past. It is a comment that seems to remind us of the argument that some European surnames have their origins in nicknames, which implies that nicknames predate surnames in some parts of Europe.

Our interest is on Ghanaian nicknames (nicknaming cultures), however, just as the literature unearths differences and nuances between communities in their use and treatment of nicknames, an examination of other nicknaming cultures can be potentially productive. While in nicknames we have a basic stratum that transcends cultural differences as it evokes human proclivities, yet paripassu vistas and possibilities exist that are culture and society-specific and furnish further insights into popular culture, social history, environmental influences, and so on. This was not lost on Pina-Cabral (1984) when he observed that functionalist and psychological explanations of 
nicknames cannot be powerful enough if they omit the community perspectives.

Colourful and loud as African names may be, they seem comparatively understudied. Ghanaian nicknames cannot be said to have fared any better, unlike southern European nicknames which have received considerable attention in the literature. In Africa some of the earliest comments on African names include Evans-Pritchard (1953) cattle names among the Nilotic Nuer of Sudan; they are names given by youth to their favourite ox, and given the centrality of ox in Nuer life and religion, bull and its master become associated such that a youth shares his ox's name. ${ }^{5}$ Note that for Evans-Pritchard, 'names of all kinds are social documents, which fix a person's position in the social structure and define his relations to other members of society' (Tatira 2004: 85). The literature on African and Ghanaian names features Majubane (1975) on Shona nickname given to District Commissioners; ${ }^{6}$ Oduyaye (1972) on Nigerian names and their meanings; Tatira (2004) on Shona dog names-an instrument of indirect communication between individuals; Pongweni (1983) on nomenclature; Ubahakwe (1981) on Igbo names; Koopman (1992) on Zulu ox- and dog-names; Madubuike's (1976) handbook; and others. In addition to Odotei (1989), Ghanaian names are treated by Dakubu (1981; 2000), Awedoba (1996), and Fortes (1955), among others. Contrary to the view that names are vacuous, Odotei (op. cit.) found in them coded information on the history, social organisation, beliefs, values and customs of the $\mathrm{Ga}$ people, since names provide clues to

\footnotetext{
${ }^{5}$ See also Evans-Pritchard's (1948) 'Nuer Modes of Address' in Uganda Journal vol. 12.

${ }^{6}$ It remains a common practice in rural communities to give names to visiting foreigners including missionaries and anthropologists; since these are not the actual names of the people in question, these names can be said to fall within the nicknames' category.
} 
lineage identification, an individual's seniority within the family, the circumstances of birth, etc. ${ }^{7}$

If we agree with Dakubu (2000) who laments that Ghanaian names have not been adequately researched and written about, then when it comes to nicknames the silence seems eerie. Contrary to expectation Rattray's works of 1927 and 1932, which scholars still refer to as the veritable compendiums of ethnographic information on Ashantis and Northern Ghanaian peoples, say nothing about nicknames. It seems to suggest, unfortunately, that nicknames are not a subject deserving of academic endeavour. ${ }^{8}$

In essaying the characteristics of Ghanaian nicknames sight should not be lost of the ethnic composition of the country. Ghana did not predate the colonial era. Its boundaries took some time to consolidate and this did not happen until Independence eve. Colonisation bequeathed to the country its current official language-English. Nevertheless, the country has many vibrant ethnic communities and although most speak Atlantic-Congo languages of the Kwa and Gur groups, mutual intelligibility is lacking. With the dominance of English and the Akan languages many Ghanaian languages can at best be described as more or less in-group communication media-

\footnotetext{
${ }^{7}$ The Ga people are usually regarded as the 'indigenes' of Accra, Ghana's capital. They share kinship affinities with the neighbouring Dangmespeaking peoples. For hegemonic reasons the 'Ga-Dangme' label was introduced as a cover term for the two groups.

${ }^{8}$ It is worth noting that one explanation may be that whatever scholarly information exists on the subject may be embedded in book chapters and ethnographic accounts under captions that do not contain the key term 'nickname'. Take Nketia (1955) for example: though focused on funeral dirges nevertheless it provides an informative account of Akan names: what that author calls 'by-names', 'dirge names' and 'praise appellations'. Dakubu (1981), for example, contains an informative discussion of $\mathrm{Ga}$ appellatives-both lineage and personal appellations. ${ }^{8}$ Some of the Ga 'Sablan' borne by individuals qualify as nicknames. Dakubu (1981: 131) remarks that they '... are often a kind of personal motto, expressing the bearer's feelings about life'.
} 
languages not current beyond their 'home' districts. While this may be so, all languages continue to serve as sources for the names that Ghanaians bear. In the cosmopolitan situation where migration and urbanisation dating back to early colonial times brought and continues to bring together peoples from various ethnic backgrounds, there have been difficulties coping linguistically with compatriots' names that are unfamiliar.' How do those who know that their compatriots have difficulties pronouncing and writing their names deal with this challenge? For some, nicknames are the answer, being easier to recall, because of their imagery, and to pronounce, because they have pidginized. ${ }^{10}$ Given the Ghanaian penchant for nicknames, call it 'alias', appellations, 'Guy' names, or whatever, it can be asked whether there is no multiplication of names, and if that fact has any social and legal implications. The issue of nicknames in the Ghanaian context thus transcends phonetics and phonology.

\section{Conceptualising Nickname in some Ghanaian Languages}

Ubahakwe (1981) suggests that unravelling the structure and meanings of nickname utterances can be a useful line of investigation. It is indeed pertinent to enquire what some Ghanaian languages make of nickname.

When asked for the Akan term for 'nickname' some Akan respondents, for example, suggested mmrane after a moment of thought. The Akan words for name (din) and nickname (mmrane) are unconnected etymologically, but the former is the base for the derivation of other name types such as abodin (by name). Mmrane is also considered the term to

\footnotetext{
${ }^{9}$ In the case of Accra, the nation's capital, every ethnic group in Ghana is found, though the major groups, according to the 2000 census reports, are the Akan (39.8\%), Ga-Dangme (29.7\%) and Ewe (18\%). Together these account for about $87.5 \%$. This should leave us in no doubt about the minority status of the remaining groups and their languages.

${ }^{10}$ Pidginization involves linguistic hybridisation and simplification.
} 
represent both the idea of nickname and appellation. The Akan appellation may, among other things, be either an honorific accorded to chiefs, or a subsidiary name associated with the pool of common Akan names that any Akan person might be given at birth. The name 'Acheampong', for example, has as its appellation 'Owoahene' or 'Otuo'; the name Antwi has 'Boasiako'; Agyeiwaa has Jkodec, etc. '

Dagaba informants could not suggest a word for 'nickname', though they have sie and dannu as terms for what an informant called 'teasing names' and praise names respectively. The Ga people have gbei for 'name' and sabla for praise name and appellation. Chamba, a Northern Ghanaian group, have diyi for name but do not seem to have a word for nickname. Nawuri have keti for 'name' and kedelebe for appellation. The immediate constituents of the Nawurikedelebe, as suggested by an informant, are kedele'praise' and -be 'small'. In the Kasem language, the word for 'name' is yere and that for nickname is baseini, which is derived from the verb seini, 'to praise or flatter'. In Kasena nicknames have positive rather than negative connotations. It is 'something that praises'. While not always endearing, as the Greek term suggests, the canonical meanings of the terms for nickname in some Ghanaian languages seem on the whole to reflect positive rather than negative features of evocation.

The Ghanaian nickname can be said to be alias, a name or names that a person or group may be called by unofficially. Though usually regarded as 'informal' names the degree of informality may vary; pseudonyms, and some assumed names or nom de guerre are of course formal as they stand in place of

\footnotetext{
${ }^{11}$ Nketia (1955: 30-33) shows that Akan distinguish between day name (kradin), proper name given at birth (dinpa), appellation (abodin), and dirge name (nsubaa). For Nketia, mmrane is by-name. He shows that appellations are also associated with day names: Kwasi (Akwasi) and Akosua (male and female Sunday-borns respectively) go with Bodua as their appellation.
} 
the given names of the individual. Royal appellations in Ghanaian cultures are very much formal, as they should accompany the name of the royal personage in formal settings. So important are these that in the past wars could be initiated because a chief took offence at a vassal chief's perceived attempts to adopt an appellation that seemed to challenge the authority of his superior. In the 1990s one chief's claim to the appellation odeneho (lit. he owns his body) caused resentment.

\section{The Giving of and Attitudes towards Ghanaian Nicknames}

The seeming lack of a term for nickname in some Ghanaian languages would at first sight suggest that nicknames are uncommon in these communities. Theories put forth by southern European researchers of nicknames suggest that the demographic conditions of communities determine the prevalence of nicknames. For example, they are said to thrive in small scale rural communities, as Brandes (1975: 147) argues: 'The nickname phenomenon flourishes where settlements are small, egalitarian, and traditional enough to provide for the moral unity and effective informal sanctioning mechanisms.' In the case of Ghana, however, there is no statistical evidence to suggest demography has bearing on the prevalence or otherwise of nicknames in the different communities. The impression is that they are common everywhere in Ghana-in rural and urban communities-and almost everybody has or has had a nickname at one time or the other.

A number of factors explain nicknames. Membership of the peer group and its dynamics is one example. Youth peer group exert pressures to conform and members share many things in common. Members play and even jostle each other; they may insult and abuse each other with impunity. They have their jokes, fads, and mannerisms including speech patterns. Nicknames bond and oil a peer group. Members may call themselves by names that are different from the formal names 
that individuals are known by. In some sense this can be compared to the playful banter and jostling that obtains, especially among youth.

The assumption of new identities associated with initiation into a group often calls for a new name. It can be seen as part of the rites of passage. Within groups involved in clandestine activities nicknames not only mark belongingness but also protect the identity of the individual members thus guaranteeing protection from easy identification and arrest in the case of criminals. Some recently apprehended armed robbers in Ghana have names such as 'Taller', 'Red', etc., which are nicknames.

The definition of nickname as given by the MWD, as indicated above, explains that nickname 'is different from your real name but is what your family, friends, etc., call you when they are talking to you or about you'. In the Ghanaian context, however, certain categories of kin and affines may not address a relative by his/her nickname. Nevertheless, nicknames may be given to certain people by their juniors; it enables underlings to talk disparagingly about their seniors without provoking reprisals. At the lower levels of education, i.e. primary and secondary schools, teachers tend to be nicknamed by their pupils. Such names may or may not be abusive. For example, a teacher teaching General paper to a sixth form class in the 1970s used the apparently unfamiliar phrase-'social malaise' in his first encounter with a class. 'Malaise' immediately became the nickname by which students referred to him. Ghanaian students would usually latch on to a teacher's pet idiom to nickname him. Even headmasters are not spared, especially if their management is deemed to be deficient in some way. One headmaster was nicknamed Quasimodo after a character in Victor Hugo's Hunch Back of Notre Dame. ${ }^{12}$

\footnotetext{
${ }^{12}$ As Ghanaian teachers are expected to be disciplinary, headmasters and staff are not exactly likable persons.
} 
Disrespect and contempt may trigger nicknames that denigrate. Unapproved behaviours and habits can be sources of nicknames. Demented people in Ghanaian towns and cities often acquire nicknames. This can result from their odd behaviours and utterances, as Azure describes in his column in Myjoyonline. ${ }^{13} \mathrm{~A}$ mad man was named 'Blue Blue' because he wore only blue clothes; another was called 'Bonjour', because he spoke French and his favourite greeting was "bonjour", irrespective of the time of the day. A Fulani mad man was called 'Alhaji' because he wore what looked like a Muslim cleric's cap. 'Dzolefimi' often shouted, "Dzo le fimi!' ('Get away' in Ewe) at people who crossed her path. 'Mebebom' (in Twi: I am going to slap) slapped people and he continuously shouted "mebsbom" whenever he met people. 'Coat Coat' was a Kumasi mad man who wore a coat stuffed with title-tattle. As the public found entertainment in the behaviours of mad and demented people on the streets, their nicknames gained popularity.

Shared experiences and their recall may furnish a basis for nicknames. The resultant nicknames are sometimes used in reciprocal address by those with the shared experience. The nickname in this case may or may not be abusive. It may spring from an episode which may not even have anything to do directly with the group who use the nickname. Classmates and the old boys and girls of a school often recall and use such nicknames long after they have left school and put the experience behind them. ${ }^{14}$

\footnotetext{
${ }^{13}$ See 'Manasseh's Folder: Mensa Otabil and the mad women of KeteKrachi'

<http://www.myjoyonline.com/opinion/2014/August-19th /manassehsfolder-mensa-otabil-and-the-mad-women-of-kete-krachi.php>, accessed 19 August 2014.

${ }^{14}$ In a first year University class a particular female student from an elite girls' secondary school tended to respond to many of the questions asked by the lecturer. In doing this she seemed to the rest of the class to use an affected accent. Then one of the male students whispered 'Ostentatious
} 
Uncanny resemblances in appearance and behaviour may lead to a person being nicknamed after another. A person may be nicknamed after another person, real or fictional, or after an animal, a thing or even an artefact that the person resembles or bears some perceived similarity to, or whose attributes the individual is perceived to exhibit knowingly or unwittingly.

Nicknames are given for various reasons. Nicknames based on dislike or disrespect aim at maligning the nicknamed individual. But the issue goes beyond personal dislike or animosity or contempt; in some cases nicknames are associated with affection and endearment, even if they do not seem to praise. Nickname giving can constitute a show of camaraderie. Those considered to be accustomed to doing the unconventional or not conforming with expected cannons of behaviour may be given nicknames, just as those with visible and identifiable peculiarities — such as physical attributes, may qualify for nicknames. People who have distinctive ways of expressing themselves, i.e. they exhibit remarkable characteristics in their idiolects may be stigmatised by a nickname. Equally, those who excel or are outstanding or are popular may be nicknamed.

Nickname may be unrelated to the formal name that the individual bears, however, they can also be derived from the formal name. Some people bear nicknames that are shortened forms of their formal names. This can transpire, in some cases, where the formal name is not easy to pronounce, perhaps because it is in a different language or it is too long; or where the shortened name sounds good and is fun to pronounce. A name like Awedoba, though apparently simple, has been shortened to 'Awe'; Akilagkpa became to some 'Aki'; Sarkodie, 'Sako'.

girl'. From this the nickname 'Ostentie' came into being and was used in reference to the female student at her back. However, eventually a group of her classmates began addressing themselves as 'Ostentie'. 
The use of initials in the coinage of nicknames is also popular in Ghana. For example, Flight Lieutenant Jerry John Rawlings is known popularly as 'JJ'. ${ }^{15}$ Like him John AgyekumKufour become JAK on assumption of the presidency. Similar to the use of initials in the coinage of nicknames name truncation and ellipsis occur frequently. Though not unknown in the past, its popularity is more recent. In some Ghanaian cultures where a name may be many syllables long-perhaps a sentence or two strung together, shortening becomes inevitable even for mother tongue speakers of the language in which the name is an utterance. The Kasena name Nakwebabaennabante (The elderly do not tell fibs, if you do you will be killed by the ancestors) is two sentences put together; even native speakers of the source language find it too long and they therefore substitute the ellipsis Nabante (If you tell lies you will be killed) or Nakwebabae (An elder does not lie). The Ewe names: Akpenamawu (Thanks be to God), Mawulawey (God will do it), and Mawusenam (God has heard my prayers) are abbreviated as Akpene, Lawey, and Esinam respectively. Likewise, in the same language, the name Afedemenya (Every house and their problem) becomes Afede.

Related to the phenomenon of deriving nicknames from name truncation we have nicknames resulting from the lisping of names by infants. Infants, when they begin to talk, call their parents and senior siblings by the names that they hear others call them by. However, they end up lisping names. Such mispronunciations are often encouraged in cultures where the names of seniors are not to be called out by those of the child

\footnotetext{
${ }^{15}$ At the height of Jerry John Rawlings popularity in 1979, JJ (Jerry John) was made to stand for 'Junior Jesus', which stemmed from a perception that Rawlings' botch putsch had redeemed Ghanaians from the clutches of the ruling generals in the 1970s. Between them General KutuAcheampong, (later 'demoted' to 'Mr.Acheampong'), and General F. W. K. Akuffo, ruled Ghana for nearly a decade (1972-1979) until they overthrown and subsequently executed.
} 
generation. This happens to be the case among the Kasena and, one would imagine, in many Ghanaian cultures where etiquette and good form demand that a person of the younger generation does not address older people by name. ${ }^{16}$ In the family of one of the authors of this paper we have the following nicknames: 'Daadane' from Kodaadeyerane, 'Titi' from Kanyisi, and Sampoa becomes 'Ampoa' while Awozeiliba becomes 'Bebe'. Among Dagombas 'Nlae' [rilae] is a reduction ofAbudulai (Dakubu 2000). ${ }^{17}$ These mispronunciations initiated by maybe the first-borns are adopted by younger siblings, and by second and third junior generation kin.

As intimated, unsavoury nicknames are usually resented by those that the names refer to and it is usually behind their backs that these names are mentioned. However, some of such names may eventually become accepted even by the person that the nickname refers to. There have been cases where wives call their husbands by their peer nicknames, though at first sight such names are derogatory. The nickname Ayi (Mr. Eye) in Kasem did not have a pleasant beginning, as it was a derogatory reference to the nickname bearer's big or bloodshot eyes. Nevertheless with time it gained popularity. In some cases, children call their father by a nickname that originated as an insult. The paradox is that while it amounts to breach of taboo to call the parent by his/her birth name in Ghana, using a nickname to address or refer to the parent becomes an individual's way out.

Just as others may give a person a nickname, some individuals adopt their own nicknames. It stands to reason that in these cases the individual would coin or select a nickname

\footnotetext{
${ }^{16}$ Nketia (1955) remarks that a junior person does not address a senior person by his/her first name. This is generally true in Ghanaian cultures.

Ghanaian University students address their lecturers and professors as 'sir', 'Madam' or 'Prof'.

${ }^{17}$ The name Sulley [sule] which is used independently may have been derived from Suleyman.
} 
that reflects a desired ideal image of himself or herself. For example, the Ghanaian football legend, AbediAyew, it would seem, either chose to call himself 'Pele' in his formative years or earned the nickname from his dribbling skills. Some Ghanaians select the names of their heroes. There was for example the bizarre case of this Ghanaian who adopted the name 'Gunnar Jarring' and called himself Gunnar Jarring Acheampong in obvious admiration of the Swedish diplomat who played a key role in the Middle East peace negotiations in the 1960 s and 1970s.

Ghanaian nicknames are not associated with only individuals; some groups have nicknames for themselves or been conferred on them collectively. In the Ghanaian political landscape, these days we hear about the 'Azoka Boys' in Tamale, the Northern Regional capital. In Bawku where there is an inter-ethnic conflict dating back to the dawn of independence we have groups calling themselves 'Taliban', 'Alkaida', etc. operating in the Bawku market place. ${ }^{18}$

\section{Conclusion}

Why the popularity of nicknames in the country? It is tempting to see the phenomenon as a manifestation of laziness-an attempt to cut corners and to avoid long names. While this explanation may not be ruled out entirely, laziness is nevertheless an inadequate explanation, especially given that some nicknames can be as long as formal names, though many are short, and easier to recall and utter.

While Shakespeare might insist on the opacity of names, we have shown in this paper that nicknames in particular often reflect the perceived character of the name bearer and his/her place in community. This is so because, as remarked above, a nickname often comes about some time

\footnotetext{
${ }^{18}$ Lund (2003) mentions youth groups operating in the Bawku market as 'Congo Boys', 'Zingaro' (the name of a cartoonist), etc. He remarks on the flamboyance of the names.
} 
after birth, either when the character of the individual has become obvious or is manifesting to neighbours and associates, or when the individual himself or herself sees the need to present and publicise an aspect of self or even vocalise hopes and aspirations.

In the multi-ethnic Ghanaian context where over 81 indigenous languages ${ }^{19}$ serve as sources for names, formal names, as we have pointed out, can be perceived to be a handful for those who do not speak the language from which the birth name originates. Thus, for example, the Nankani name Amengaetego can be heard pronounced by non-speakers of Gur languages as 'Amengo'. It also seems reasonable that a long name like the Kasena 'Nabiinabachegatea' which is a proverb sentence comprising subject, negative marker, object and verb, should be shortened to 'Nabina' (see Awedoba 1996). Adopted names, pseudonyms, nicknames or name ellipsis may thus come to the public's rescue in a country with a high diversity ratio. ${ }^{20}$ Inter-ethnic convenience alone cannot however suffice as explanation for adoption of nicknames. A related issue would be some members of minority ethnic groups who adopt nicknames and alias as a means to gain better acceptance in cosmopolitan public settings. A similar approach goes back to the colonial times when surnames like 'Grunshie', 'Frafra', 'Kanjaga', 'Dagarti', 'Wala', etc. were adopted by Northern Ghanaian migrants in southern Ghana first came into being. The objective then was, among other things, to assert membership of an ethnic community, and to avoid having to use one's birth name which would pose problems for reference in the work place where the employers and senior employees are from a different ethnic group.

Peer group and its dynamics and the clandestine activities of members of a group make adoption of nicknames

\footnotetext{
${ }^{19}$ See $<$ http://www.ethnologue.com/statistics/country $>$, accessed 4 February 2015.

${ }^{20}$ The country's diversity ratio (based on number of languages, their speakers, and their genetic relationships) is put at 0.81 by ethnologue.
} 
necessary as it not only marks belongingness but also protects the identity of affiliates. Affection and endearment, dislike, disrespect and contempt, uncanny resemblances in appearance and behaviour and the use of initials in the coinage of nicknames may trigger nicknames. The usage and popularity of nicknames is not lost to Ghanaians as everywhere in Ghana-in rural and urban communities, almost everybody has or has had at least one nickname at one time or the other.

*Albert Kanlisi Awedoba, Institute of African Studies

University of Ghana, Legon, Accra, Ghana akawedoba@ug.edu.gh

*Stephen Owoahene-Acheampong, Institute of African Studies, University of Ghana, Legon, Accra

Ghana, soacheampong@ug.edu.gh 
Awedoba \& Owoahene-Acheampong: What is in a nickname...

\section{References}

Awedoba, A. K. (1996). Kasem Nominal Genders and Names.Research Review New Series 12(1\&2): 8-24.

Awedoba, A. K. (2007).Gender and Kasena classification of things. In: Studies in the Languages of the Volta Basin 4,Mary E. KroppDakubu, G. Akanlig-Pare, E. K. Osam and K. K. Saah (eds.), pp. 28-42. Legon-Proceedings of the Colloquium the Annual Colloquium of the LegonTrondheim Linguistics Project, Part 1: Nominal Constructions. Barnes, R. H. (1980).Hidatsa Personal Names: An Interpretation. Plains Anthropologist 25(90): 311-331.

Brandes S. H. (1975).The Structural and Demographic Implications of Nicknames in Navanogal, Spain.American Ethnologist 2(1): 139-48.

Carter, W. A. (1944).Nicknames and Minority Groups.Phylon 5(3): 241-245.

Connolly, M. R. (2000).What's in a Name? A Historical Look at Native American-Related Nicknames and Symbols at Three U.S. Universities.The Journal of Higher Education 71(5): 515-547.

Dakubu, M. E. K. (2000).Personal Names of the Dagomba. Research Review New Series 16(2): 53-65.

Dakubu, M. E. K. (1988).The Languages of Ghana. New York: Kegan Paul.

Dakubu, M. E. K. (1981).One Voice: the Linguistic Culture of an Accra Lineage.Leiden: African Studies Centre, University of Leiden.

Evans-Pritchard, E. E. (1953).The Sacrificial Role of Cattle among the Nuer. Africa: Journal of the International African Institute 23(3): 181-98.

Evans-Pritchard, E. E. (1948). Nuer Modes of Address. Uganda Journal 12: 166-71.

Fortes, M. (1955).Names among the Tallensi of the Gold Coast. AfrikanisticheStudien 26: $337-49$. 
Gilmore, D. D. (1982).Some Notes on Community Nicknaming in Spain. Man, New Series 17(4): 686-700. Glazier, J. (1987).Nicknames and the Transformation of an American Jewish Community: Notes on the Anthropology of Emotion in the Urban Midwest.Ethnology 26(2): 73- 85.

Green, A. (1991).The Double-Edged Sword: Nicknames on the New Zealand Waterfront, $1915-1951 . O r a l$ History 19(1): 53-55.

Koopman, A. (1992).The Socio-Cultural Aspects of Zulu Oxand Dog-names. Nomina Africana 6(1): 1-13.

Lund, C. (2003). 'Bawku is still volatile': ethno-political conflict and state recognition in Northern Ghana. Journal of Modern African Studies 41(4): 587-610.

Madubuike, I. A. (1976).A Handbook of African Names. Washington, DC: Three Continents Press.

Majubane, E. (1975).African Names of Native and District Commissioners. NADA11(2): 253-255.

Manasseh, A. A. (2014).Manasseh's Folder: Mensa Otabil and the mad women of Kete-

Krachi<http://www.myjoyonline.com/opinion/2014/August-

19th/manassehs-folder- mensa-otabil-and-the-mad-

women-of-kete-krachi.php>, accessed 19 August 2014.

Naden T. and R. Schaefer (1973).The meaning of Frafra.Research Review 9(2): 5-12.

Needham, R. (1975).Polythetic Classification: Convergence and Consequences.Man New Series 10(3): 349-369.

Newman, P. and M. Ahmad.(1992).Hypocoristic names in Hausa.Anthropological Linguistics 34: 159-72.

Nketia J. H. (1955).Funeral Dirges of the Akan People. Achimota: (no publisher).

Odotei, I. (1989).What is in a Name? The Social and Historical Significance of Ga Names. Research Review New Series 5(2): 34-51. 
Awedoba \& Owoahene-Acheampong: What is in a nickname...

Oduyaye, M. (1972).Nigerian Names 1, Yoruba Names: Their Structure and Their Meanings. Ibadan: Daystar Press.

Pina-Cabral, J. de.(1984).Nicknames and the Experience of Community.Man New Series 19(1): 148-50.

Pongweni, A. J. C. (1983).What's in a Name? A Study of Shona Nomenclature.Gweru: Mambo Press.

Rattray, R. S. (1927).Religion and art in Ashanti. London: OUP.

Rattray, R. S. (1932).Tribes of the Ashanti Hinterland vols. 1 \& 2. Oxford: OUP.

Riviere, P. (1971).Marriage: A Reassessment. In: Rethinking Kinship and Marriage, R. Needhan (ed), pp. 57-74. London: Tavistock Publications.

Sarpong, P. (1974).Ghana in Retrospect: Some Aspects of Ghanaian Culture. Accra-Tema: Ghana Publishing Corporation.

Tatira, L. (2004).Beyond the Dog's Name: A Silent Dialogue among the Shona People. Journal of Folklore Research 41(1): 85-98.

The Merriam Webster's Collegiate Dictionary. 2014. $<$ http://www.merriam-webster.com/dictionary/nickname>, accessed 10 October 2014.

Ubahakwe, E. (1981).Nigerian Names 2, Igbo Names: Their Structure and Their Meanings. Ibadan: Daystar Press. 